\title{
EXPANSÃO, DIVERSIFICAÇÃO, DEMOCRATIZAÇÃO: questões de pesquisa sobre os rumos do ensino superior no Brasil ${ }^{1}$
}

\author{
INTRODUÇÃO
}

\author{
Maria Ligia de Oliveira Barbosa*
}

Este dossiê é resultante de uma proposta de pesquisa financiada pelo Conselho Nacional de Desenvolvimento Científico e Tecnológico (CNPq) e que visava à criação de uma rede institucionalizada de pesquisa sobre o ensino superior no Brasil, reunindo especialistas de diferentes estados e universidades. Visava a articular alguns trabalhos que já vinham sendo desenvolvidos, de forma a permitir a convergência temática e metodológica dos estudos sobre ensino superior no Brasil. A formação do grupo permitiu a realização de encontros (um nacional e outro internacional) dos pesquisadores envolvidos na constituição dessa rede. O encontro nacional, feito em BH em setembro de 2012, deu origem, em 2014, ao livro "Ensino Superior: expansão e democratização", da editora 7Letras. Já o encontro internacional, realizado no Rio, em novembro de 2013, resultou nos textos ora apresentados. Acreditamos que avançamos na pesquisa e no debate sobre o en-

* Universidade Federal do Rio de Janeiro, Instituto de Filosofia e Ciências Sociais, Departamento de Sociologia. Largo de São Francisco, 1. Centro. Cep: 20051070. Rio de Janeiro - Rio de Janeiro - Brasil. mligiabarbosa@gmail.com ${ }^{1}$ Este dossiê é parte de um trabalho coletivo no Laboratório de Pesquisa sobre Ensino Superior do CNPq/UFRJ. Agradeço a todos os colegas e a todos os estudantes que colaboraram nos diversos estágios até aqui desenvolvidos. Em especial, gostaríamos de agradecer as sugestões, críticas e encorajamentos de Clarissa Baeta Neves, Elizabeth Balbachevsky e Helena Sampaio. sino superior e que os seis trabalhos apresentados delineiam alguns dos elementos fundamentais para dar conta dessa realidade diversificada e complexa, mais ou menos eficiente, mais ou menos desigual, mais ou menos justa.

Nesse encontro, o Seminário Internacional Democratização do Ensino Superior, criouse a oportunidade para analisar algumas das principais questões que se desenham nesse campo da pesquisa em ciências sociais. O ensino superior é aquele nível de escolarização que tem, basicamente, duas funções: formar profissionais para o mercado de trabalho (reproduzir conhecimento) e lidar com a questão do conhecimento (produzir conhecimento e formar pessoas para produzir esse conhecimento). Nesse quadro, a sociologia do ensino superior, tal como foi formulada por Gumport (2007), teria um viés pragmático, buscando analisar qual é o problema atual das universidades em relação ao conhecimento e porque elas teriam problemas ao lidar com as mudanças sociais contemporâneas (Gripp; Barbosa, 2014). A essa perspectiva, mais pragmática ou política, podem-se acrescentar algumas questões de caráter mais eminentemente sociológico. O que está subjacente às mudanças? Que mudanças sociais estão na base dessas mudan- 
ças aparentes? O que está subjacente aos desafios colocados às universidades?

Conforme Gripp e Barbosa (2014), o que está subjacente a essas questões são disputas sociais sobre o que é universidade e para que a universidade serve. Pergunta-se, também: quais os grupos sociais que disputam a definição de universidade? Como esses grupos se compõem e se recompõem no tempo? O que está em jogo nessa disputa? Que tipo de resultados é obtido? Como se distribuem esses resultados socialmente? Da perspectiva de Gumport (2007) esse seria o primeiro subcampo da pesquisa sobre ensino superior, ao qual se acrescentam o problema dos impactos sociais do ensino superior e os estudos sobre a profissão acadêmica e sobre as organizações e instituições universitárias. Gripp e Barbosa (2014) indicam também a relevância de se compreender mais adequadamente as formas de produção e reprodução do conhecimento no ensino superior, destacando a dimensão das diferenças disciplinares associadas à divisão técnica do trabalho, inclusive científico.

O tema das desigualdades sociais permite focalizar tanto as questões do acesso diferenciado ao ensino superior como aquelas relativas à permanência e ao sucesso. Na verdade, há uma infinidade de questões associa-

$\stackrel{2}{\sigma}$ das ao tema que, muitas vezes, sobrepõem os - subcampos mencionados por Gumport. Estão incluídas aí as pesquisas sobre financiamento, políticas e análises institucionais, habilidades o e sucessos dos estudantes, escolha da instituição, status socioeconômico e família, diversidade étnica, cultural e social.

$+\quad$ Obviamente, trata-se de subcampos que $\dot{*}$ tratam do mesmo objeto a partir de perspectivas $\stackrel{\infty}{N}$ e abordagens distintas, mas que, muitas vezes, $\dot{\Delta}$ desenvolvem argumentos e análises muito próximos. É o que se verifica nos estudos do impacto do ensino superior, que se refeririam ao

[...] domínio das pesquisas sobre os efeitos das características da estrutura formal das instituições e do meio social normativo e da natureza social dos estudantes que reforça ou enfraquece os efeitos da universidade/faculdade. Dentro deste domínio estão situadas as pesquisas que lidam com a questão da evasão, a questão do ambiente do campus e a coesão social, a questão da retenção, estudos sobre a socialização nas instituições de ensino superior, estudos sobre características estruturais e o seu impacto nos estudantes (tamanho institucional, seletividade, composição racial) (Gripp; Barbosa, 2014, p. 31).

No interior desse quadro de discussões, o texto inicial do dossiê, "Qual democratização do ensino superior?”, conferência realizada por François Dubet no seminário, evidencia a complexidade das relações sociais nesse espaço. Com a fineza característica de sua abordagem, Dubet procura distinguir analiticamente as várias dimensões da democratização, baseadas, por sua vez, em concepções diferentes da justiça. Associando a melhor tradição da sociologia francesa com as contribuições da economia e da filosofia sobre as relações entre desigualdade e justiça, o autor mostra as relações entre as concepções de igualdade de oportunidades, meritocracia, utilidades e equidade dos procedimentos, e os modos mais ou menos democráticos de funcionamento do ensino superior. Cada sociedade constrói modelos de democratização desse ensino, dependendo de sua trajetória histórica e da configuração de forças sociais presentes. A massificação do ensino superior desempenhou papel democrático objetivo, favorável aos grupos sociais antes excluídos, tanto mulheres quanto diversas outras minorias culturais ou étnicas. Mas massificação não equivale a democratização. Todas as categorias sociais não se beneficiam da mesma forma da massificação. Nesse ponto, Dubet abre o diálogo com outros textos neste dossiê, indicando que a democratização do acesso ao ensino superior não depende apenas das famílias. Mesmo que abram mais e mais possibilidades de entrada no ensino superior, a democratização do acesso dependeria também da estrutura geral do sistema educativo. Segundo o autor, esses sistemas tenderiam a desenvolver um tipo de meritocracia acadêmica que construiria uma hierarquia de competências. Essa hierarquia teria não só um caráter eminentemente social, mas também 
um forte impacto reprodutivo das hierarquias propriamente sociais. Com isso, as desigualdades de utilidade ou valor social das diferentes formações e diplomas acabam por ter impacto significativo sobre o conjunto das desigualdades sociais. Visando a aumentar as chances de permanência de todos os estudantes, os sistemas educativos criam distintos procedimentos de seleção, de concessão de gratuidades, bolsas, auxílios, que podem ser considerados como mais ou menos equitativos segundo as normas de justiça que mobilizam.

Talvez esse seja o ponto em que fica mais clara a necessidade de análise cuidadosa das políticas públicas para o ensino superior: as aparências enganam. Propostas generosas, com as melhores intenções, podem ter efeitos sociais profundamente injustos. Exemplos não faltam.

Conjugando temas relativos à democratização do ensino superior com as transformações do sistema a partir de tendências internacionais que se desenvolvem em cada país, o texto de Simon Schwartzman discute a "Demanda e políticas públicas para o ensino superior nos BRICS”. Analisando a expansão do ensino superior nos países incluídos nesse acrônimo, Brasil, Rússia, Índia, China e África do Sul, Schwartzman mostra que aspiração generalizada e crescente pelo ensino superior obriga os governos a gerirem os custos de funcionamento desse sistema. A análise, fundada num conjunto impressionante de pesquisas sobre o tema, indica que, em cada país, houve respostas que variaram segundo sua história, cultura e regime político. Dentro do leque imenso de diferenças, o autor estabelece parâmetros para comparações que permitem fazer avançar a análise dos processos sociais envolvidos em cada caso. Todos eles enfrentaram problemas semelhantes, como escassez de recursos e o poder político de atores do sistema de ensino superior e fora dele. Como bem sabemos, as percepções e a valorização que cada sociedade constrói sobre os seus sistemas de ensino são bastante diferenciadas, mesmo dentro dessas sociedades. Grupos sociais diferentes têm expectativas e demandas quanto ao ensino superior que chegam a ser mesmo opostas. E cada grupo social tem distintas estratégias e formas políticas de pressionar o Estado e a sociedade para tentar imprimir, no sistema de ensino, os modelos que julgam melhores. Segundo Schwartzman, cinco dilemas se apresentam aos países analisados: (1) expansão, igualdade de acesso e diversificação das matrículas, taxas de participação, o número e os tipos de instituições; (2) limitações financeiras; (3) regulação do ensino superior privado; (4) como fazer com que as instituições de ensino superior prestem mais contas a seus alunos, funcionários e à sociedade como um todo; e (5) qualidade e relevância social da aprendizagem e pesquisa em instituições de ensino superior. Cada um deles configura, por si só, um grande projeto de pesquisa. Mas a síntese produzida mostra respostas comuns, com algumas exceções em cada caso: diversificação institucional; políticas de ação afirmativa; crescimento das matrículas nas ciências sociais, humanidades, profissões sociais e educação; e pouco sucesso nas políticas de internacionalização.

Se o Brasil interessa mais diretamente, é importante destacar uma diferença de nosso país em relação aos outros BRICS no que diz respeito à diversificação institucional. Nos demais países, essa diversificação tomou a forma de diferenciação de investimentos, com apoio a algumas instituições que se destacariam das demais e buscariam atingir padrões internacionais. Existe uma aposta brasileira num modelo único, humboldtiano, segundo Schwartzman, que não conseguiu impedir a intensa diversificação de formas de funcionamento. Poder-se-ia completar essa perspectiva indicando que o viés acadêmico que marca o nosso modelo único de ensino superior tende a produzir ineficiências em quase todas as suas dimensões (Barbosa, 2014).

Outra exceção brasileira que mereceria destaque, particularmente considerando o texto de François Dubet, é o pagamento de mensalidades pelos estudantes, mesmo em instituições públicas. A gratuidade oferecida nas instituições públicas brasileiras, aquelas que formam o 
topo da hierarquia acadêmica brasileira, colide com alguns dos princípios de justiça e com as políticas de igualdade de oportunidades educacionais. Esta gratuidade pode ter impactos muito fortes de reprodução social, os quais, provavelmente, já foram reduzidos nos outros BRICS.

Outro tema ou linha de pesquisa sobre ensino superior apontada por Gumport seria a aproximação das universidades das normas do mercado. Enquanto tendências sociais podem ser indicadas nesse tema, há uma porosidade crescente em relação às normas da economia ou às reconfigurações institucionais que transparecem, por exemplo, na diversificação de financiamento e no desenvolvimento de centros de pesquisas interdisciplinares para responder a demandas sociais. A relação entre globalização econômica e educação superior pode ser analisada como parte do processo de aproximação das normas do mercado, principalmente pelo seu impacto tanto nos modelos do que deva ser uma "world class university" quanto pela crescente mobilidade internacional de professores e, principalmente, de alunos. E, nessa questão, o artigo de Carlos Benedito Martins, "Notas sobre a formação de um sistema transnacional de ensino superior", é exemplar.

Nesse texto, o autor discute os processos que reorganizam o ensino superior em cada soเ్็ ciedade contemporânea, não mais confinado aos limites nacionais, atingindo espaços cada vez mais abrangentes que as fronteiras geográficas. Criar-se-ia, então, o que Martins chama de espaço transnacional, onde cada instituição, necessariamente, se insere em teias relacionais

\& acadêmica, cada vez mais presente, caracteriza-

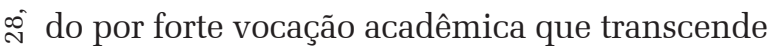
$\vec{s}$ suas fronteiras nacionais e pelo foco principal na pesquisa como um mecanismo de desenvolvimento econômico e social. Além disso, esse novo modelo teria também eficiência científica e gerencial, num quadro em que o investimento na ciência associa-se a retornos para o desenvolvimento econômico e social. O interes- sante é que a perspectiva adotada indica toda a complexidade dos processos envolvidos na construção de modelos bem sucedidos de universidades modernas e de alta qualidade. Processos que vão do recrutamento internacional de professores, alunos e, mesmo, de gestores até a participação ativa em diversas instituições e agências, públicas e privadas. Claro que isso inclui tanto desterritorialização, através da instalação de campi em vários países, bem como a mobilidade internacional dos estudantes. O processo, fortemente relacional, de formação de sistemas transnacionais de ensino superior leva à valorização dos rankings internacionais e a busca pela criação das chamadas universidades de classe mundial. A entrada de cada universidade, de cada sistema de ensino superior, nessa corrida é uma decisão autônoma da instituição e da sociedade. Mesmo que uma instituição não possa ter autonomia absoluta, de resto inexistente, ela tem a liberdade de definir seus objetivos e missões. E pode decidir participar dessa luta sem tréguas que caracteriza o sistema transnacional de ensino superior.

Novamente, pensando no caso brasileiro, depara-se com dificuldades razoáveis, como já foi mencionado no texto de Schwartzman. Num diálogo direto, Martins afirma que o país deveria desenvolver políticas específicas para determinadas instituições com características que permitissem aspirar à chegada aos padrões mundiais de excelência.

Para tanto, é fundamental desatar os nós asfixiantes do centralismo burocrático estatal, implementar uma efetiva autonomia institucional, incrementar o recrutamento de professores e estudantes estrangeiros e analisar criticamente a pertinência de um paradigma isonômico que se encontra presente em várias dimensões das universidades federais.

A criação desse espaço transnacional seria parte do processo de expansão global dos sistemas de ensino superior. Como já mostrou muito claramente a literatura, essa expansão recobre os mais diversos aspectos da vida social, dos princípios de hierarquização às formas de nutrição das crianças (Baker, 2014), e não pode 
ser desvinculada da expansão das democracias e dos direitos humanos pelas diferentes regióes do mundo (Schofer; Meyer, 2005). Seja pela autonomia buscada nos sistemas universitários, seja pela expansão da demanda dos estudantes e de suas famílias, esse quadro torna a transparência das políticas e das práticas no ensino superior uma exigência comum. Também a necessidade de prestação de contas foi globalizada. E é exatamente como elemento constitutivo cada vez mais demandado no processo de expansão do ensino superior que o acompanhamento dos egressos do sistema torna-se objeto de pesquisa. O texto de Jean Jacques Paul, "Acompanhamento de egressos do ensino superior: experiência brasileira e internacional”, oferece uma oportunidade rara na literatura brasileira, de compreender os significados dos diferentes dispositivos existentes para realizar esse trabalho. Seria importante mencionar a experiência do Professor Jean Jacques Paul tanto na elaboração de questionários e instrumentos de acompanhamento quanto na direção de instituições responsáveis por esse tipo de pesquisa. Tendo trabalhado e dirigido instituições universitárias na França, no Brasil e na Turquia, ele também teve papel destacado no funcionamento do IREDU, da Universidade da Borgonha, onde se criou um laboratório para acompanhamento das trajetórias estudantis. Seu artigo permite conhecer e discutir, de forma aprofundada, os meandros desse tipo de pesquisa.

No artigo, Paul traça um panorama bastante abrangente das diversas experiências de acompanhamento de egressos do ensino superior, destacando as metodologias utilizadas nos diferentes países ou em projetos internacionais. Destaque-se que os diferentes dispositivos de acompanhamento resultam de políticas governamentais ou de instituições autônomas que buscavam e buscam dar maior visibilidade ao sistema de ensino superior, cada vez mais complexo. Fornecendo subsídios essenciais para a avaliação dos resultados dos sistemas educativos, os dispositivos de acompanhamento atingiram os melhores indicadores de funcionamento no caso italiano, o AlmaLaurea. ${ }^{2}$ Instituição chave para as relações entre a universidade, os universitários e as empresas, ela apresenta formas metodológicas de trabalho com resultados expressivos, não encontrados em outros casos. No Brasil, há experiências díspares, que começam nos anos 1970, passando pelos estudos na Universidade de São Paulo (USP) e Universidade Federal do Ceará (UFC) no início dos 1990, até o estágio atual, com a proliferação de portais de egressos.

As diferentes estratégias de acompanhamento de egressos são marcadas por exigências metodológicas severas, conforme indica a experiência conhecida e reconhecida. Do ponto de vista institucional, é necessário dar um caráter sistemático a esse acompanhamento, garantindo também o esforço participativo: os alunos e ex-alunos precisam se disponibilizar a fornecer as informações. Institucionalmente. sistematicidade significa que deve haver uma periodicidade regular, bem conhecida, e com atualização permanente. É essencial a utilização de tecnologias da informação para coleta de dados. Torna-se muito relevante, também, uma definição clara e adequada da população a ser atingida, segundo os tipos de diplomas: não só os certificados são diferentes, como também os seus portadores. Não são meros indivíduos que fornecem informações, mas profissionais de determinado tipo, com determinada identidade coletiva. Finalmente, uma exigência lógica, mas bastante difícil, pois implica trabalho interdisciplinar e conhecimento do trabalho em áreas de pesquisa nem sempre próximas dos profissionais da educação superior: trata-se da necessidade de produção de escalas adequadas para a avaliação dos destinos ocupacionais e sua relação com a formação. Pesquisas desse tipo só teriam a ganhar com a disponibilização de seus bancos de dados para a comunidade acadêmica. Tendo já avançado em algumas dimensões da análise sobre o sistema de ensino superior brasileiro no contexto de mudanças sociais e de aprofundamento de sua inserção no espa${ }^{2}$ Acesso disponível em: < http://www.almalaurea.it/>. 
ço global, damos ênfase, agora, à contribuição dos estudos sobre as organizações. O enfoque organizacional tem importantes contribuições na análise das instituições de ensino superior, tratando desde a questão da multiplicidade e diversidade dessas instituições até a questão da governança, incluindo o trato com as lideranças de todos os segmentos e os impactos do ambiente externo. O texto de Prates e Barbosa, "A expansão e as possibilidades de democratização do ensino superior no Brasil”, utiliza alguns dos instrumentos dessa abordagem para destacar as dificuldades do processo de democratização do ensino superior, mesmo num contexto de expansão maciça das matrículas.

Como já foi evidenciado, nosso sistema de ensino superior expandiu-se e diversificouse nas últimas três décadas. O artigo discute, então, as possíveis tendências de sua modernização e democratização, participando do debate colocado pelos textos anteriores. No caso, busca desenvolver questões fundamentalmente associadas aos valores socialmente atribuídos aos diplomas do ensino superior, ou sua utilidade, para usar o termo de Dubet. O ponto essencial em torno do qual se organiza o argumento seria a relação entre o domínio quase absoluto de uma visão patrimonialista sobre o ensino superior e o esgarçamento dos conteúdos científicos e (ou) pedagógicos associados aos diversos diplomas. O patrimonialismo seria caracterizado, do ponto de vista empírico, em primeiro lugar, pela preferência pelo bacharelado, em detrimento dos diplomas de licenciatura e tecnológicos. Uma segunda dimensão desse patrimonialismo apareceria nas vocações socialmente marcadas: alunos provenientes das classes populares tendem a ter vocações menos nobres que seus colegas mais influentes. Uma dimensão forte do que se chamou de patrimonialismo, na gestão dos sistemas de ensino superior, seria a organização dos horários e turnos dos diferentes cursos e modalidades. Outra manifestação do patrimonialismo poderia ser vista, de forma bastante difusa, no desinteresse pelas áreas técnicas e no domínio de uma pedagogia do cultivo. Mais ainda, o patrimonialismo aparece na dialética entre saberes e a força social dos diplomas. A possível instalação de um credencialismo radical no Brasil permite analisar a relação entre o domínio patrimonial e a cultura profissional, indicando os limites da democratização do sistema de ensino superior.

Justamente para começar a criar caminhos de análise sobre a democratização do sistema de ensino superior e seus limites, tomamos um estudo de caso sobre estudantes desprivilegiados que frequentam um curso pouco valorizado, da área de educação, numa instituição de prestígio, a Universidade Federal do Rio de Janeiro (UFRJ). O texto de Heringer e Honorato, "Elementos para uma análise dos estudantes cotistas e bolsistas no curso de Pedagogia da UFRJ”, aborda a produção das desigualdades no ensino superior nesse ponto crucial.

$\mathrm{O}$ artigo trata da grande expansão das oportunidades de acesso à educação superior no Brasil, com ênfase especial ao caso de uma de suas maiores e mais prestigiadas instituições - a Universidade Federal do Rio de Janeiro, começando pelas dificuldades metodológicas encontradas na construção de instrumentos de levantamento de dados, como são o survey e as entrevistas semiestruturadas. Em se tratando de um curso cujos estudantes têm, comprovadamente, uma origem social mais modesta e pais menos educados que a média da universidade, o arco de problemas encontrados é bastante amplo: desde o desconhecimento de informações básicas sobre o funcionamento da universidade - inclusive sobre as possibilidades de acesso às diversas bolsas - e mesmo de localização dos prédios da Faculdade de Educação, até a recusa de discutir assuntos delicados como a renda e a estrutura familiar. Tudo se torna muito complicado, qualquer que seja o instrumento, questionário ou entrevista. Esses instrumentos foram utilizados para analisar o caso dos alunos do curso de Pedagogia com ingresso em 2011 e 2012 (primeiras turmas com reserva de vagas para estudantes de escolas públicas). Como foi mencionado, esses estudantes têm um perfil, já histórico, de dificuldades econômicas e culturais para a conclusão dos estudos. As autoras sintetizam alguns dos limites e desafios potencialmente colocados nos estudos que pretendem contribuir para o planejamento, o desenho e a implementação de políticas institucionais de democratização do acesso, da permanência e de assistência àqueles que são 
chamados de novos estudantes. Dessa forma, o texto se associa às diversas questões trabalhadas ao longo dos diversos artigos neste dossiê. Diretamente ligado ao texto de Paul, o artigo em pauta abre espaços para a reflexão sobre a democratização do ensino superior em várias das dimensões analisadas. Mas talvez a sua importância maior seja a de ressaltar o complexo jogo de entendimentos, desentendimentos e parcialidades de perspectivas envolvidas na efetivação de uma política pública.

No conjunto, esses textos impulsionam o conhecimento sobre os avanços e os limites da democratização de um ensino superior que se expande buscando ser mais inclusivo. Entretanto, a entrada massiva de estudantes provenientes de setores antes excluídos não democratiza necessariamente esse nível de ensino. Como destacam Dubet e Prates e Barbosa, as formas de funcionamento do sistema de ensino superior devem ser objeto de estudos mais detalhados. Há ainda muita pesquisa a ser feita sobre o quanto as práticas sociais no interior desse sistema podem ou não contribuir para o oferecimento de oportunidades iguais para todos os estudantes. Esses estudantes que agora chegam à universidade são, muitas vezes, originários de grupos sociais com distintas percepções e demandas para o ensino superior, como mostrou o artigo de Schwartzman. E, nesse contexto, a diversificação institucional aparece como uma resposta comum, não só no Brasil. Pergunta-se, então, se o domínio de um modelo humboldtiano de universidade reforçaria a reprodução das desigualdades sociais através dessa diversificação que parece ser perversa. Supondo que esse seja um mo- delo eficiente, a produção de tantos universitários de perfil humboldtiano é possível? Ou necessária? A valorização quase exclusiva do modelo de viés acadêmico no ensino superior é eficaz para a sociedade que sustenta essa valorização? Essa questão pode ser pensada tanto pela lógica do mercado, cada vez mais presente nos sistemas de ensino superior, como mostrou Martins, ou pela lógica da justiça, como propõe Dubet. Do ponto de vista prático ela pode ser respondida, pelo menos em parte, através dos dispositivos de acompanhamento de egressos analisados por Paul. Eles permitiriam não só decidir sobre alguns tipos de formação, mas também iluminariam vias novas para a pesquisa sobre os sentidos socialmente atribuídos ao ensino superior.

Recebido para publicação em 10 de abril de 2015 Aceito em 17 de abril de 2015

\section{REFERÊNCIAS}

BAKER, David P. The schooled society: the educational transformation of global culture, Stanford, California, Stanford University Press, 2014. 342 p.

BARBOSA, M. L.O. O ensino superior no Brasil: credencial, mérito e os coronéis. In: (Org.): Ensino superior: expansão e democratização. Rio de Janeiro: Ed. 7 Letras, 2014. p. 51-69.

GRIPP, G.; BARBOSA, M. L. O. 2014. A sociologia da educação superior: ensaio de mapeamento do campo. In: BARBOSA, M. L. O. (ed.). Ensino superior: expansão e democratização. Rio de Janeiro: 7 Letras, 2014. p. 9-36,

GUMPORT, Patricia (Ed.). Sociology of higher education. Contributions and their contexts, Baltimore: The John Hopkins University Press, 2007.

SCHOFER, E.; MEYER, J. W. The Worldwide Expansion of higher education in the twentieth Century. American Sociological Review, v. 70, n. 6, p. 898-920, 2005. ISSN 0003-1224. Disponível em:<http://asr.sagepub.com/ content/70/6/898>.

Maria Ligia de Oliveira Barbosa - Doutora em Ciências Sociais. Professora da Universidade Federal do Rio de Janeiro, Instituto de Filosofia e Ciências Sociais, Departamento de Sociologia Coordenadora do Laboratório de Pesquisa em Ensino Superior/UFRJ/CNPq (LAPES). Tem experiência na área de Sociologia, com ênfase em Sociologia da Educação, atuando principalmente nos seguintes temas: desigualdades sociais, hierarquias sociais, ensino superior e profissões, políticas públicas. Vice-Presidente para América Latina do RC04 - Sociology of Education - da ISA (International Sociological Association) 2010-2014 e 20142018. Publicações recentes: Esboço de uma morfologia da sociologia brasileira. RBS - Revista Brasileira de Sociologia, v. 1, p. 147-178, 2013; The expansion of higher education in Brazil: credentials and merit. Multidisciplinary Journal of Educational Research, v. 3, p. 251-271, 2012; Desempenho individual e organização escolar na realização educacional. Revista Sociologia \& Antropologia, v. 02, p. 159-184, 2012. 
